2020, Volume 10, International Conference Globalization, Innovation and Development. Trends and Prospects (G.I.D.T.P.), pages: 172-179 |

https://doi.org/10.18662/lumproc/gidtp2018/20

\section{Mathematics - a Transdisciplinary Approach: Interference in Economy}

\section{Ioana MIHAI (SICRIERU)*', Anisoara DUICA ${ }^{2}$}

${ }^{1}$ Valahia University of Târgoviste, Targoviste, Romania, e-mail: mihai_ioana2005@yahoo.com

2 Valahia University ofTârgoviste, Targoviste, Romania, e-mail: anisoara_duica@yahoo.com

Corresponding author
Abstract: This paper presents briefly the notions of interdisciplinarity, pluridisciplinarity, transdisciplinarity and their importance in modern society, but at the same time proposes an interdisciplinary approach between mathematics and various sciences or fields of activity, taking into account that in recent years, universities, institutions research and funding agencies have made great efforts to encourage interdisciplinary research.

Keywords: knowledge; interdisciplinarity; mathematics; pluridisciplinarity; transdisciplinarity.

How to cite: Mihai (Sicrieru), I., \& Duica, A. (2020). Mathematics - a Transdisciplinary Approach: Interference in Economy. In I. Panagoreț \& G. Gorghiu (vol. ed.), Lumen Proceedings: Vol. 10. International Conference Globalization, Innovation and Development. Trends and Prospects (G.I.D.T.P.) (pp. 172-179). Iasi, Romania: LUMEN Publishing House. https://doi.org/10.18662/lumproc/gidtp2018/20 


\section{Introduction}

The times in which the individual of the company, be it a student, an employee, an employer, or a manager, was turned into some patterns, they have gone. Now, in the digital age, the speed of information and the technology to which mankind has reached have, as expected, been capturing the horizon of education. Thus, in a continuous struggle for survival or supremacy and in a terrible change of poles, the modern man must withstand an assault of demands that flow in unmercifully. The learning process changed its essence, the idea of the former teacher and its role being updated to the notion of daily requirements. The teacher who conveys information and has the role of mentor for the mind and character of the student has also been forced to adapt. The pupils of the third millennium now have the courage to be leaders, to take responsibility and develop into key roles in the team, are pro-social through training, and why not, selftaught. They are not afraid to change on the go, to play their chances, to develop and develop their thinking from the beginning, whether we are talking about the critical one or the artistic one. As a matter of fact, it became clear that by trans disciplinary, students left behind the pattern of storing information at a deep pace. The student of the present needs challenges, new situations to test his limits and thinking. The modern student applies what he knows what he has learned without fear and progress and because of the transfer of information and curiosity.

Education also means knowledge that provides an immutable concept. Thus, the transdisciplinarity we find more and more often in projects that relate to this horizon must break the patterns of dissemination, which has not once led to an erroneous assent. It is imperative for its perception to be achieved by a correct transposition of the principles of transdisciplinarity. This will avoid conceptual confusions and, categorically, distractions that aim at applying a transdisciplinary theory.

It is, therefore, necessary to use an interdisciplinary, multidisciplinary and transdisciplinary approach to achieve optimal results using mathematical information in all areas we know. Mathematics recurs in the simplest of everyday life, being, in my opinion, the science with the highest applicability in all fields of activity, especially in the real sciences: physics, chemistry, computer science; but also in social ones, such as economics, psychology, and sociology; engineering or humanities. As GrigoreMoisil states in "A man like any other," we can say that "as it matures, a science mathematizes." 


\section{Inter-, Pluri-, Transdisciplinary Approach}

BasarabNicolescu said that "Disciplinarity, multidisciplinarity, interdisciplinarity and transdisciplinarity are the four arrows of one and the same arc: the one of knowledge" [3].

The contribution of each discipline should not be constituted by the specificity of the disciplines, but by what they have in common, the transferable elements, elements that ensure the general character. If, through the monodisciplinary approach of learning, special competencies are formed, the interdisciplinary, multidisciplinary and transdisciplinary approach creates integrative and sustainable skills through their own transferability.

Interdisciplinarity (the prefix inter means between) represents the horizontal transfer of knowledge and methods from one discipline to another through which new disciplines can be created. Interdisciplinarity appears as a necessity to exceed the artificial boundaries between different areas, covering the lack of correlations between disciplines and building dynamic, flexible, responsive mental structures capable of supporting the most appropriate decisions [7]. Interdisciplinarity involves phenomena, concepts and general laws common to several disciplines that are analyzed in contexts as varied as possible to highlight the multiple facets and the possibilities of their application in the sphere of various disciplines [1].

Interdisciplinarity seeks to answer the questions: "What are the possible interdisciplinary ways of presenting and organizing knowledge?"And "What are the main advantages and disadvantages of each presented way?"

According to B. Nicolescu we can distinguish three degrees of interdisciplinarity:

- an applicative degree in which, after the transfer of methods, it results concrete practical applications;

- an epistemological degree in which, following the assimilation of methods in other fields, profitable analyzes of his own epistemology are initiated within the discipline;

- a generating rate of new disciplines where the transfer of methods between two or more disciplines leads to the emergence of an autonomous field.

Interdisciplinarity represents the knowledge transfer from one discipline to another (e.g. from mathematics to economics, from mathematics to informatics, from mathematics to phisics) in which the limits of a discipline are permanently reshaped, but still original, in order to improve the learning and teaching process. Interdisciplinarity always requires cooperation with other disciplines, although it is very innovative and also unifying [5]. 
Pluridisciplinarity (or multidisciplinarity) is the study of the subject of a discipline by methods belonging to several disciplines. Thus, multidisciplinarity is a superior form of interdisciplinarity, and consists in the overlapping elements from various disciplines, which should collaborate, thus, a theme, belonging to a certain field, is being analised from the perspective of several disciplines, maintaining their structure unaltered, remaining independent of each other [8].

The pluridisciplinary approach pervades the limits of disciplines, but its purpose remains within disciplinary research.

Transdisciplinarity aims at what is at the same time within the various disciplines, between disciplines and beyond any discipline, leads to the intensification of the relations between disciplines and the discovery of new horizons of knowledge.

"Transdisciplinarity concerns - as the trans-prefix indicates - what is at the same time between disciplines and within the various disciplines, and beyond any discipline, its purpose is understanding the present world, one of its imperatives being the unity of knowledge" [3].

Transdisciplinarity is based on the maximization to the fullest of interdisciplinary, beeing a form of complex multidisciplinarity, defined as academic purpose. By transdisciplinarity we mean the perfect combination of knowledge from different sciences in to one big science universe (epistemological multiverse) [6].

The transdisciplinary approach is explained by BasarabNicolescu as based on three methodological postulates:

- The ontological postulate, which implies the existence of several levels of reality, each level having a set of laws or general norms inappropriate for the other existing levels of reality.

- The logical postulate or logic of the included third party, which presupposes the existence of a third term, which is also $\mathrm{A}$ and nonA.

- The epistemological postulate, which assumes acceptance of complexity, because the complex and integrated nature of modern society issues such as globalization, migration, interculturality, environmental protection, information explosion, conflicts, calls for a transdisciplinary educational approach.

Transdisciplinarity is the interpenetration of several disciplines, in the form of curricular integration, with the possibility of creating, over time, a new discipline or a new field of knowledge through fusion - the most radical phase of integration [4]. The integrated approach, specific to transdisciplinarity, is folded, adapted to the real world, on the relevant 
aspects of everyday life, presented as affecting and affecting our lives, but this does not mean that disciplines will cease to exist as such.

\section{Interference between Mathematics and Various Fields}

Grigore Moisil said that „all that is right-thinking is either mathematics or susceptible to mathematics" and thought that "by learning math, you learn to think".

The mathematical competence of an individual presupposes the commissioning of all mechanisms related to the direct contact with the real through sensations, perceptions, representations; the symbolic mediation of reality - by notions, concepts, judgments, reasoning; complex psychic mechanisms - memory, thinking, imagination and energizing and supportive activity - through attention, will and affective-motivational mechanisms. Mathematical competence implies the activation of the abilities and mechanisms described above, and mathematical conduct involves engagement, self-motivation and appeal to previous experience in mathematics, based on potential competence.

Nowadays, all sciences use the results of the work of mathematicians, and many other fields are generated by mathematics itself. Mathematics has proven useful in many others domains and has brought together the general issues of mathematical concepts. As in many other areas, the explosion of knowledge in science has led to specializations in mathematics. The study of systems of equations and inequalities allows to demonstrate, on some examples, the solutions of certain economic problems related to linear programming, and in the same sense can be mentioned also the notions of statistic and probability theory - one of the largest branches of mathematics with reverberations interdisciplinary and its study requires the input of a large number of new and unusual notions.

Many fields of applied mathematics have merged with fields that traditionally were outside of them and have become new disciplines such as statistics, operational research, math physics, chaos theory, game theory, computer science, cryptography, econometrics.

For example, between physics and mathematics there is a remarkable connection, physics providing concepts and relationships, and mathematics offering an optimal language for their expression. With all the differences of objects and methods of knowledge, physics cannot dispense with the mathematical language and apparatus. Mathematics allows the concentrated expression of dependencies between the physical magnitudes that occur in phenomena, dependendences that often serve to define the notions. The importance of mathematics in physics derives from the fact that a short 
mathematical formula often replaces a long verbal exposure on a physical subject.

Knowledge of mathematics, for example, notions such as: proportions, proportion properties, report strings, three simple rule, percentages, etc. they are also applicable in understanding and appropriately acquiring the notions of chemistry (atomic mass, molecular mass, molar mass), fundamental chemistry laws (the law of substance mass preservation, the law of proportions defined, gas law) and chemical calculations (percentage composition, calculations based on chemical reaction formulas and equations, concentration of solutions, solving problems with mixtures of solid, liquid or gaseous solutions) [2].

\section{Mathematics and Economy}

The presence of mathematics in the economy is accompanied by so many examples of application that we no longer have to prove it. The application of mathematics in economic science and practice is one of the most important orientations of the development of economic theory and the improvement of the system of planning and conducting of the national economy. Economic and mathematical studies have undergone a number of developmental phases: the first stage has been characterized by the development of balancing models such as the balance of branch relationships, as well as mathematical programming models, such as linear programming models (models based on (parabolic, hyperbolic model, power function model, exponential model, logarithmic model, and logarithmic parabola model)) used in experimental economic calculations. In the second stage, the researchers focused mainly on the elaboration of optimization methods of different types and on their practical application in solving planning problems. Numerous economic and mathematical models have been developed, based on which calculations were made for the development of real optimal plans (optimal transport plans, rolling stock exploitation, fuel use, equipment utilization enterprises, optimal territorial distribution of different branches of industry and enterprises of an industrial frame, optimal planning and distribution of investments, etc.), which ensured a significant effect in the national economy. For the third stage, it is characteristic of the synthesis orientation of the theoretical researchers and the development of the systemic approach by the practical use of the economical-mathematical models.

In economic sciences, especially in management, econometric modeling is often encountered and applied regardless of the level investigated. The patterns are used in all their variety of types, and in the last 
decades the tendency to use mathematical models has become more and more prominent, due to the increased accuracy they have. Among the most common models are the econometric models. They describe the behavior of economic phenomena using systems of mathematical equations in which numerical elements are statistically determined.

The use of mathematics in the economy has created a whole complex of scientific disciplines, to which tens of thousands of specialists from all sectors of economic science and from all the links of the national economy contribute today. (The Dictionary of Mathematics and Cybernetics in Economics).

Nowadays, mathematical tools are indispensable to modern scientific research in the economic field. The integration of forecasting techniques of economic and social phenomena, the widespread use of data processing and the analysis of data tools and metadata tools are ways to provide the basis for an integrated scientific research into future phenomena and processes.

\section{Conclusions}

Although transdisciplinarity is so often confused with interdisciplinary and multidisciplinary, it is completely erroneous to assert that these three notions would designate the same thing, even if this is large because all three subvert the limits of discipline. Transdisciplinarity is radically distinct from multidisciplinary and interdisciplinary through its purpose the understanding of the present world a finality that cannot fit into disciplinary research. The finality of multidisciplinary and interdisciplinary is always disciplinary research. This confusion is very damaging to the extent that it overcame the different ends of these three ways of approaching knowledge. Interdisciplinary multiplies disciplinary boundaries, while transdisciplinarity transgresses them. Pluridisciplinarity remains between disciplinary boundaries, meanwhile the transdisciplinarity is looking for and what lies within and beyond them. In economy, the applicability of mathematics is essential. Without the necessary mathematical notions, an economic entity cannot calculate its earnings or losses, in order to determine the level of profitability. The mathematical apparatus is used in its entirety because mathematical logic and reasoning, as well as mathematical notions, formulas and tools are very important for the establishment of budgets, for calculating the profitability of an investment, economic activity, and for making optimal decisions. 


\section{Acnowledgment}

This work was supported by a grant of the Romanian National Authority for Scientific Research and Innovation, CCCDI - UEFISCDI, project number 39/BM.

\section{References}

[1]. Augsburg T. Becoming Interdisciplinary: An Introduction to Interdisciplinary Studies. Kendall Hunt Publishing; 2006.

[2]. Davis E, Davis JP. Mathematics, Substance and Surmise - Views on the Meaning and Ontology of Mathematics. New York: Ed. Springer; 2015.

[3]. Nicolescu B. Transdisciplinaritatea: Manifest. Traducere din limba franceză de Vasilescu HM. Iasi: Ed. Junimea; 2007.

[4]. Petrescu P, Pop V. Transdisciplinaritatea - o nouă abordare a situațiilor de învăţare. Bucureşti: Ed. Didactică şi Pedagogică; 2007.

[5]. Săvoiu G, Dinu V, Tăchiciu L. An Inter-, Trans-, Cross- and Multidisciplinary Approach to Higher Education in the Field of Business Studies. Anfiteatru Economic. 2014; XVI (37): 712-713.

[6]. Săvoiu G. Iorga Simăn I. Multidisciplinaritatea şi educația academică. Dialoguri argumentate. Bucureşti: Editura Universitară, 2011.

[7]. Wikipedia. Interdisciplinarity. Available from: https://en.wikipedia.org/wiki/Interdisciplinarity [Accessed 3rd February 2020].

[8]. Tribuna invatamantului. Available from: http://test.tribunainvatamantului.ro/ [Accessed 3rd February 2020]. 